\title{
An Improvement of Electromotive Force in Switched Flux Permanent Magnet Generator by using Multi-Tooth Technique
}

\author{
Pattasad Seangwong ${ }^{1}$, Siripat Somchit ${ }^{2}$, Kanokphon Kaisoda ${ }^{3}$, Phuson Srikhumphun ${ }^{4}$, Kornchanok Suwanpaiboon ${ }^{5}$, \\ Warat Sriwannarat $^{6}$, Apirat Siritaratiwat ${ }^{7}$ and Pirat Khunkitti ${ }^{8, *}$

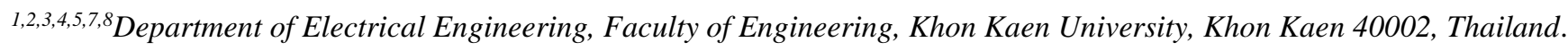

${ }^{6}$ Department of Electrical and Computer Engineering, Kasetsart University Chalermphakiet, Sakon Nakhon Province Campus, Sakon Nakhon 47000, Thailand.

*corresponding author

*ORCID: 0000-0002-4331-0688

\begin{abstract}
This paper proposed a design technique to improve the electromotive force (EMF) of the switched flux permanent magnet (SFPM) generator by using the Multi-tooth technique. The simulations were carried out through the 2-D finite element method. The configuration of stator pole and rotor pole as well as the number of electrical phases were modified based on the principle of Multi-tooth technique. The output characteristics of the proposed generator structure including the magnetic field distribution, phase flux linkage, EMF and cogging torque were characterized and were compared with those of the conventional SFPM generator. The symmetrical property of magnetic field distribution was firstly confirmed. Then, the results indicated that the proposed multi-tooth SFPM generator can produce $4 \%$ higher EMF than the conventional model at same rotational speed. The EMF waveform of the proposed structure was indicated better smoothness than that of conventional structure. Meanwhile, the cogging torque scale of the proposed structure was slightly improved from the conventional structure. From the results, it was obviously seen that the proposed multi-tooth SFPM generator requires only half volume of permanent magnet compared to the conventional structure, while indicating the better EMF scale. Therefore, the proposed multi-tooth SFPM generator can be valuable choice for manufacturing in the SFPM generator, this structure could significantly reduce the usage of a permanent magnet which usually dominates the overall cost of the generator fabrication.
\end{abstract}

Keywords: Rotating Electric Machines, Permanent magnet machine, Permanent magnet generator, Switched flux permanent magnet generator, Multi-tooth technique, Electromotive force

\section{INTRODUCTION}

The renewable energy has received much attention for an electrical generation, especially during the past few decades. In order to produce the electrical power from the renewable energy i.e wind and hydro energy, the permanent magnet (PM) machines have been widely focused because of their outstanding characteristics such as no field excitation and better thermal management [1-3]. The PM machines can be divided into 2 types depending to the location of the PM, namely, the stator permanent magnet machine (SPM) and rotor permanent magnet machine. The SPM can be categorized into 3 types according to the location of installed PMs, including the doubly silent permanent magnet machines, the flux reversal permanent magnet machines and the switched-flux permanent magnet (SFPM) machines. Especially, the SFPM machine has been appropriately used in automobile industries as well as wind power generation system [4]. Remarkably, the SFPM generator can provide the great electrical characteristics such as high torque density, electromotive force (EMF) and output power [5]. The EMF is an important factor of generator that indicates the ability to produce the voltage of the generator. A symmetrical property of the EMF waveform can also indicate the torque ripple profile when supplying the electrical load. In 2010, the optimal stator and rotor pole combination of SFPM brushless AC machine was proposed aiming to increase the phase back EMF of the generator [6]. It was shown that the back EMF can be improved by adjusting the number of stator and rotor pole. Later on, a novel partitioned stator switched flux permanent magnet machine was presented in 2015, it was found that the generator based on multiples of stator teeth technique can achieve higher back EMF [7]. In 2019, the multiphase SFPM machine have been designed as the wind power generators [8]. The higher and more symmetrical EMF waveform could be achieved by adjusting the split ratio, the 
stator tooth width and the rotor pole width of the generator. Recently, the SFPM machine with using multi-phase technique has been investigated to enhance the electromagnetic performance and improve the control strategy $[9,10]$. However, the weakness of the SFPM generator is the high usage of PM installed in the generator structure which significantly increase the fabricating cost as well as reduce the slot area for winding coil. Accordingly, many techniques have been proposed for reducing the magnet usage, i.e. E-core [11], C-core [12] and multi-tooth [13]. Particularly, the outstanding advantage of multi-tooth technique is that this technique could essentially increase the slot area for winding coil. Then, the electrical performances of the generator such as mutual inductance, torque density, and EMF could be improved.

Then, the aim of this work is to improve the electrical characteristics of the multi-phase SFPM generator by using the multi-tooth technique. The magnetic field distribution, phase flux linkage, EMF and cogging torque were analysed in no-load condition. The performance of the conventional structure and the proposed multi-tooth SFPM structure were compared in the same dimeter. The simulation was based on the 2-D finite element method.

\section{MACHINE DESIGN}

Figure 1(a) indicates the 12-phases SFPM generator with 24/22-pole (stator/rotor-pole), this structure was proposed by Shao et al [14]. The generator configuration includes the "Ushape" of stator yoke and the permanent magnet inserted at the middle of the stator tooth. Each stator tooth is wound by the winding coil with non-concentration type. The rotor part is the salient pole without permanent magnet, winding and brushes, accordingly this rotor configuration has light weight and low inertia. In order to improve the EMF of the conventional SFPM generator, the multi-tooth technique was performed to the conventional structure, as shown in Fig. 1(b). The suitable number of stator poles $\left(N_{S}\right)$ and rotor poles $\left(N_{r}\right)$ of multi-tooth structure was introduced by [15], as given by

$$
\begin{aligned}
& N_{s}=k m \\
& N_{r}=N_{s}(2 n-1) \pm 2
\end{aligned}
$$

where $n, k$ and $m$ are the number of stator teeth, even positive integral and number of phase, respectively.

In order to perform the multi-tooth technique to the conventional structure, half of the stator teeth number of the conventional structure was firstly removed. Then, the two-teeth stator tip was made at the end of stator pole. Accordingly, the number of stator poles became 12 and the number stator teeth became 2. From equation (2), the number of rotor poles can be 35 or 37 poles. However, in order to obtain the symmetrical EMF waveform, the number of rotor pole usually set with the even number to balance the magnetic force [15]. Accordingly, the number of rotor pole can be 34 or 38 poles. From our analysis, we found that the generator with 38 rotor poles indicated a better performance than the that with 34 rotor poles, therefore the number of rotor pole of 38 will be focused in the proposed multi-tooth structure. In addition, the phase number of the multi-tooth SFPM generator has to be reduced from 12phases of conventional structure to be 6-phases due to the limitation of stator area. The main design parameters of the conventional and the proposed multi-tooth SFPM generators are given in Table 1.

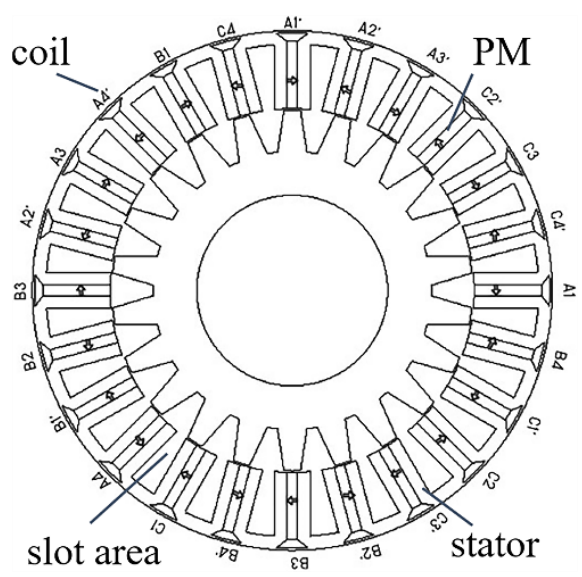

(a)

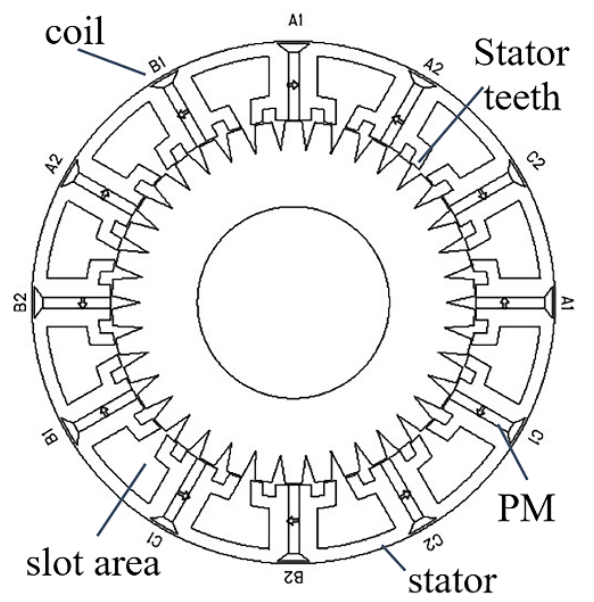

(b)

Fig. 1. Cross-section of conventional and proposed SFPM generator; (a) 24/22-pole multi-phase structure with 12-phases and (b) 12/38-pole multi-tooth with 6-phases. 
Table 1. The main design parameters of conventional and multi-tooth SFPM generators

\begin{tabular}{|c|c|c|}
\hline Item & $\begin{array}{c}\text { Conventional } \\
\text { structure } \\
{[14]} \\
\end{array}$ & $\begin{array}{c}\text { multi- } \\
\text { tooth } \\
\text { structure }\end{array}$ \\
\hline $\begin{array}{c}\text { Number of phases } \\
\text { [phase] }\end{array}$ & 12 & 6 \\
\hline Stator-pole number & 24 & 12 \\
\hline Rotor-pole number & 22 & 38 \\
\hline Magnet remanence $[\mathrm{T}]$ & \multicolumn{2}{|l|}{1.2} \\
\hline Rate rotor speed [r/min] & \multicolumn{2}{|l|}{500} \\
\hline Stack length $[\mathrm{mm}]$ & \multicolumn{2}{|l|}{185} \\
\hline Stator outer radius [mm] & \multicolumn{2}{|l|}{163.5} \\
\hline Stator yoke length [mm] & \multicolumn{2}{|l|}{8.56} \\
\hline Split ratio & \multicolumn{2}{|l|}{0.7} \\
\hline Stator inner radius [mm] & \multicolumn{2}{|c|}{114.45} \\
\hline PM length [mm] & \multicolumn{2}{|c|}{42.519} \\
\hline Cut delta length $[\mathrm{mm}]$ & \multicolumn{2}{|l|}{8} \\
\hline Air gap length [mm] & \multicolumn{2}{|l|}{1} \\
\hline Stator pole arc $\left[{ }^{\circ}\right]$ & \multicolumn{2}{|c|}{3.9375} \\
\hline Stator slot $\operatorname{arc}\left[{ }^{\circ}\right]$ & \multicolumn{2}{|l|}{3.75} \\
\hline $\mathrm{PM} \operatorname{arc}\left[{ }^{\circ}\right]$ & \multicolumn{2}{|l|}{3.375} \\
\hline Stator teeth $\operatorname{arc}\left[{ }^{\circ}\right]$ & - & 3.75 \\
\hline Rotor pole arc $\left[{ }^{\circ}\right]$ & \multicolumn{2}{|l|}{5.25} \\
\hline Rotor pole-yoke $\operatorname{arc}\left[{ }^{\circ}\right]$ & \multicolumn{2}{|c|}{12.075} \\
\hline Rotor pole height $[\mathrm{mm}]$ & \multicolumn{2}{|l|}{25.96} \\
\hline Coil turn [turns] & \multicolumn{2}{|l|}{65} \\
\hline $\begin{array}{l}\text { Stator small slot depth } \\
{[\mathrm{mm}]}\end{array}$ & - & 7.864 \\
\hline
\end{tabular}

\section{ANALYSIS OF GENERATOR CHARACTERISTICS}

In the analysis of generator characteristics including the phase flux-linkage, EMF and cogging torque, the magnetic vector potential in the z-axis, $A_{\mathrm{z}}$, was firstly derived from the Ampere's law, which is written as equation (3):

$$
\sigma \frac{\partial A_{z}}{\partial t}+\left(\frac{1}{\mu_{0}}\left(\Delta \times A_{z}-B_{r}\right)\right)=J_{e}
$$

where $B_{\mathrm{r}}$ is the remanent flux density of $\mathrm{Nd}-\mathrm{Fe}-\mathrm{B}$ permanent magnet $(1.2 \mathrm{~T}), \mathrm{Je}$ is an external generated current density (0A), $\mu_{0}$ is the vacuum permeability of air and $\sigma$ is the electrical conductivity of air.

Then, the phase flux linkage, $\psi_{\text {linkage }}$, can be obtained by using equation (4).

$$
\psi_{\text {linkage }}=N \times \frac{L}{A} \int A_{z} d A
$$

In order to calculate the EMF, the electric field in the zdirection, $E_{\mathrm{z}}$, was calculated from the $A_{\mathrm{z}}$, as shown in equation (5):

$$
\nabla \times E_{z}=\frac{-\sigma\left(\nabla \times A_{z}\right)}{\partial t}
$$

Then, the EMF can be obtained from equation (6).

$$
E M F=N \frac{L}{A} \int E_{z} d A
$$

where $N$ is the number of turns of winding coil, $L$ is the stack length in the z-axis, $A$ is the area of the winding cross-section.

The cogging torque, $T_{\operatorname{cog}}$, is generated by an interaction of PMs and the rotor saliency cores. This torque generally causes noise and vibration to the generator outputs, especially during the starting condition and low-speed operation. The cogging torque can be expressed as equation (7) [16].

$$
T_{c o g}=\sum_{h=1}^{M} T_{c h m} \sin \left(6 h P_{r} \theta_{r}+\varphi_{c o g h}\right)
$$

Where $h$ is the harmonics order, $P_{\mathrm{r}}$ is the rotor pole-pairs number and ${ }_{\mathrm{r}}$ is the rotor position. $T_{\mathrm{chm}}$ and $\varphi_{\mathrm{cogh}}$ are the amplitude and phase of the harmonics, respectively.

\section{RESULT AND DISCUSSION}

The magnetic field distribution of the conventional structure and the proposed multi-tooth structure of SFPM generator is shown in Figs. 2(a) and 2(b), respectively. It was confirmed that the magnetic flux distribution flowing through the generator structure was greatly symmetric for both structures. Remarkably, the proposed multi-tooth structure indicated lower leakage flux between the stator teeth than the conventional structure. This was due to the less PM usage of the proposed multi-tooth structure, which produce the lower intensity of magnetic flux density.

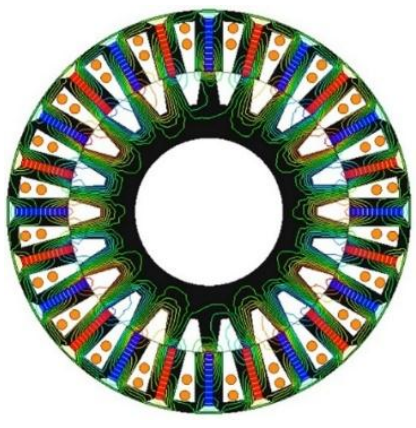

(a)

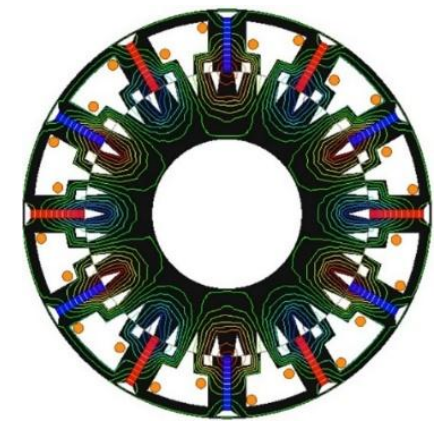

(b)
Fig. 2. The magnetic flux distribution at no-load conditions of (a) conventional structure and (b) the proposed multi-tooth structure of SFPM generator. 
Figure 3 demonstrates the open-circuit phase flux-linkage profile at no-load condition of the conventional structure and the proposed multi-tooth structure of SFPM. The symmetrical waveform of both structures was well observed. It was remarkably found that the magnitude of flux-linkage of the multi-tooth structure was lower than the conventional structure. The reason was because of a smaller number of PM installed in the generator structure, which is consistent with the magnetic field intensity shown in Fig. 2.

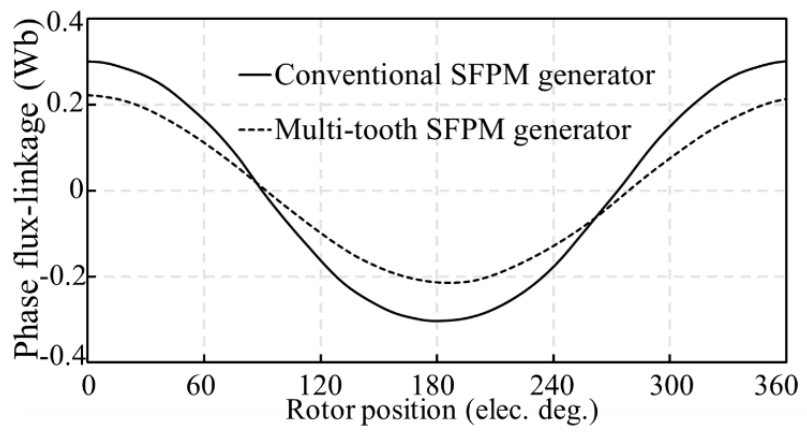

Fig. 3. The phase flux-linkage of the conventional and the proposed SFPM generators.

The no-load phase EMF waveforms of both SFPM generators at various rotor positions are shown in Fig. 4. It is seen that the maximum EMF of the multi-tooth SFPM generator is $4 \%$ higher than that of the multi-phase SFPM generator. The reason is that the multi-tooth SFPM generator has more rotor pole number than that of the conventional structure, which directly increases both of the phase flux-linkage derivative and electric frequency. Furthermore, the result indicates that waveform of phase EMF of the proposed multi-tooth structure is more smoothness than that of the conventional structure. Accordingly, this implies that the torque profile of the proposed multi-tooth structure will contain smaller ripple than that of the conventional structure as previously described in [17].

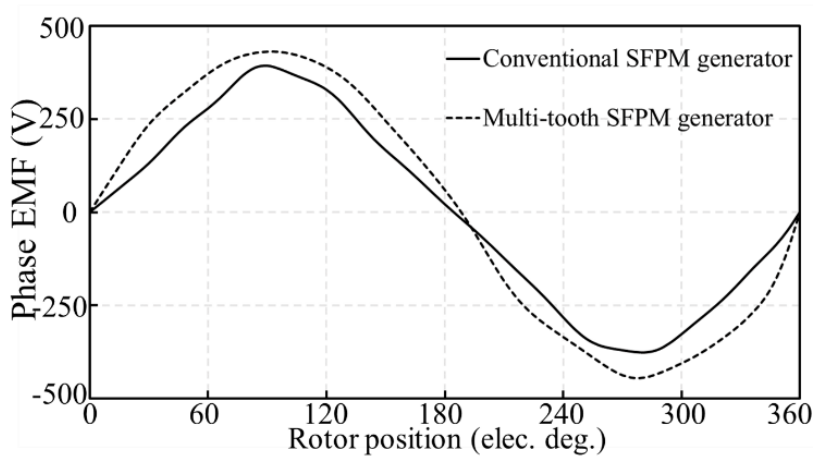

Fig. 4. The phase EMF waveforms of the conventional and the proposed SFPM generators.

As seen in Fig. 5, the cogging torque waveform of the conventional and the proposed multi-tooth structures are obtained. It is seen that the peak cogging torque of the conventional and the proposed multi-tooth structures is 41 and $37 \mathrm{Nm}$, respectively. This implies that the proposed multi-tooth structure indicates a better performance at starting condition and low-speed operation. The reason was due mainly to a reduction of the permanent magnet usage in the proposed multitooth structure.

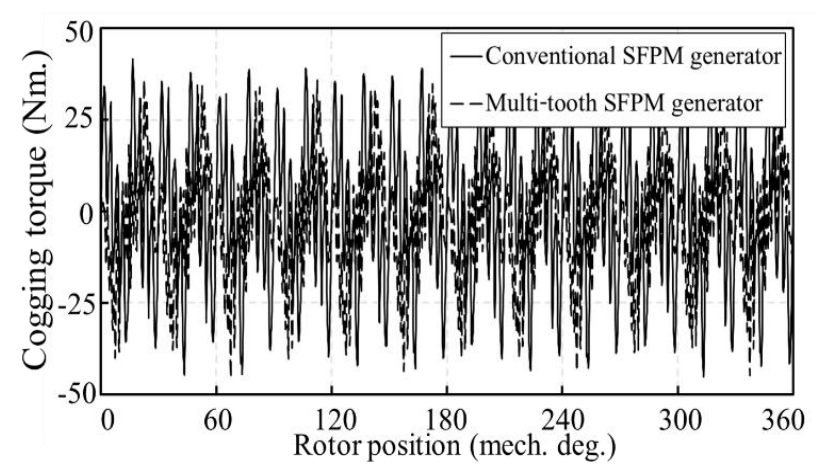

Fig. 5. The cogging torque waveforms of the conventional and the proposed SFPM generators.

From these results, it is summarized that the SFPM generator with applying the multi-tooth technique could produce higher phase EMF value and the better cogging torque than that of conventional structure. Another advantage of the proposed multi-tooth SFPM generator is that this structure requires only half of PM usage than the convention structure to produce the slight better EMF than the conventional structure, which could be benefit in term of fabrication cost. This also imply that the proposed multi-tooth structure indicates a better magnet usage efficiency than the conventional structure. Consequently, the proposed 12/38-pole multi-tooth SFPM generator could be a suitable choice for electrical generation from renewable energy source.

\section{CONCLUSION}

In this work, we proposed a design technique to improve the open-circuit phase EMF of the SFPM generator. It was firstly confirmed that the magnetic field distribution in the generator structure was symmetric. The result of phase flux-linkage indicates that the phase flux-linkage of the proposed multitooth structure was lower than the conventional structure due to a fewer magnet volume. Meanwhile, the open-circuit phase EMF produced by the proposed multi-tooth SFPM generator was $4 \%$ higher the conventional multi-phase SFPM generator indicating the better generator performance. The improved cogging torque scale was also observed in the proposed multitooth SFPM generator. In summary, the proposed multi-tooth SFPM generator requires only half volume of permanent magnet compared to the conventional structure, while indicating the better EMF and cogging torque scale. Therefore, this proposed structure could significantly reduce the generator fabricating cost which is normally dominated by the permanent magnet volume. 


\section{ACKNOWLEDGEMENTS}

This work was financially supported by the young researcher development project of Khon Kaen University and the Thailand Research Fund (grant numbers MRG6180010).

\section{REFERENCES}

[1] Cheng M, Member S, Hua W, Zhang J. Overview of Stator-Permanent Magnet Brushless Machines. 2011;58(11):5087-5101.

[2] Sriwannarat W, Khunkitti P, Janon A, Siritaratiwat A. An improvement of magnetic flux linkage in electrical generator using the novel permanent magnet arrangement. Acta Phys Pol A. 2018;133(3):642-644.

[3] Sriwannarat W, Siritaratiwat A, Khunkitti P. Structural Design of Partitioned Stator Doubly Salient Permanent Magnet Generator for Power Output Improvement. 2019;2019.

[4] Akuru UB, Kamper MJ. Optimisation and design comparison of 10-kW and 3-MW PM flux-switching machines for geared medium-speed wind power generators. Electr Eng. 2018;100(4):2509-25.

[5] Chen JT, Zhu ZQ. Comparison of all- and alternate-poleswound flux-switching pm machines having different stator and rotor pole numbers. IEEE Trans Ind Appl. 2010;46(4):1406-15.

[6] Chen JT, Zhu ZQ. Winding configurations and optimal stator and rotor pole combination of flux-switching PM brushless AC machines. IEEE Trans Energy Convers. 2010;25(2):293-302.

[7] Evans DJ, Zhu ZQ. Novel partitioned stator switched flux permanent magnet machines. IEEE Trans Magn. 2015;51(1):1-14.

[8] Shao L, Hua W, Li F, Soulard J, Zhu ZQ, Wu Z, et al. A comparative study on nine- and twelve-phase fluxswitching permanent-magnet wind power generators. IEEE Trans Ind Appl. 2019;55(4):3607-16.

[9] Li F, Hua W, Tong M, Zhao G, Cheng M. Nine-Phase Flux-Switching Permanent Magnet Brushless. IEEE Trans Magn. 2015;51(3):34-7.

[10] Thomas AS, Zhu ZQ, Owen RL, Jewell GW, Howe D. Multiphase Flux-Switching Permanent-Magnet Brushless Machine for Aerospace Application. IEEE Trans Ind Appl. 2009;45(6):1971-81.

[11] Chen JT, Zhu ZQ, Iwasaki S, Deodhar R. A novel E-core flux-switching PM brushless AC machine. 2010 IEEE Energy Convers Congr Expo ECCE 2010 - Proc. 2010;3811-8.

[12] Owen RL, Zhu ZQ, Jewell GW. Hybrid-excited fluxswitching permanent-magnet machines with iron flux bridges. IEEE Trans Magn. 2010;46(6):1726-9.

[13] Zhu ZQ, Chen JT, Pang Y, Howe D, Iwasaki S, Deodhar R. Analysis of a Novel Multi-Tooth Flux-Switching PM
Brushless AC Machine for High Torque Direct-Drive Applications. 2008;44(11):4313-6.

[14] Shao L, Hua W, Zhu ZQ, Tong M, Zhao G, Yin F, et al. Influence of Rotor-Pole Number on Electromagnetic Performance in 12-Phase Redundant Switched Flux Permanent Magnet Machines for Wind Power Generation. IEEE Trans Ind Appl. 2017;53(4):3305-16.

[15] Chen JT, Zhu ZQ, Howe D. Stator and rotor pole combinations for multi-tooth flux-switching permanentmagnet brushless AC machines. IEEE Trans Magn. 2008;44(12):4659-67.

[16] Huang W, Hua W, Yu F. A model predictive current control of flux-switching permanent magnet machines for torque ripple minimization. AIP Adv. 2017;7(5):056609.

[17] Zhu X, Hua W. Back-EMF waveform optimization of flux-reversal permanent magnet machines. AIP Adv. 2017;7(5):056613. 